\title{
Erratum to: 'Mutiny on the Bounty': the genetic history of Norfolk Island reveals extreme gender-biased admixture
}

Miles C. Benton', Shani Stuart ${ }^{1}$, Claire Bellis², Donia Macartney-Coxson ${ }^{3}$, David Eccles ${ }^{1}$, Joanne E. Curran², Geoff Chambers ${ }^{4}$, John Blangero ${ }^{5}$, Rod A. Lea ${ }^{1}$ and Lyn R. Griffiths ${ }^{1 *}$

Unfortunately, the original version of this article [1] contained an error. The spelling of the author name Lyn R. Grffiths was incorrect. The correct author name is Lyn R. Griffiths. The author name has been corrected in the original article and is also included correctly in author list above.

\begin{abstract}
Author details
${ }^{1}$ Genomics Research Centre, Institute of Health and Biomedical Innovation, Queensland University of Technology, Q Block, 66 Musk Avenue, Kelvin Grove Campus, Brisbane 4001, QLD, Australia. ${ }^{2}$ Texas Biomedical Research Institute, San Antonio 78227, TX, USA. ${ }^{3}$ Kenepuru Science Centre, Institute of Environmental Science and Research, Wellington 5240, New Zealand. ${ }^{4}$ School of Biological Sciences, Victoria University of Wellington, Wellington 6140, New Zealand. ${ }^{5}$ South Texas Diabetes and Obesity Institute, University of Texas Rio Grande Valley School of Medicine, Brownsville 78520, TX, USA.
\end{abstract}

Accepted: 23 September 2015

Published online: 07 October 2015

\section{Reference}

1. Benton MC, Stuart S, Bellis C, Macartney-Coxson D, Eccles D, Curran JE, et al. 'Mutiny on the Bounty': the genetic history of Norfolk Island reveals extreme gender-biased admixture. Invest Genet. 2015;6:11.

\footnotetext{
* Correspondence: Iyn.griffiths@qut.edu.au

Miles C Benton and Shani Stuart are joint first authors.

${ }^{1}$ Genomics Research Centre, Institute of Health and Biomedical Innovation, Queensland University of Technology, Q Block, 66 Musk Avenue, Kelvin Grove Campus, Brisbane 4001, QLD, Australia

\section{Submit your next manuscript to BioMed Central and take full advantage of:}

- Convenient online submission

- Thorough peer review

- No space constraints or color figure charges

- Immediate publication on acceptance

- Inclusion in PubMed, CAS, Scopus and Google Scholar

- Research which is freely available for redistribution

Submit your manuscript at www.biomedcentral.com/submit 